\title{
Ergonomic Factors in Patenting Computer Systems for Personnel's Selection and Training"
}

\author{
Valery Spasennikov ${ }^{10000-0002-4378-3426]}$, Kirill Androsov ${ }^{\text {[0000-0002-7894-5405] }}$ and Galina \\ Golubeva ${ }^{2[0000-0002-7906-6779]}$ \\ ${ }^{1}$ Bryansk State Technical University, 241035 Bryansk, Russia \\ spas1956@mail.ru, androkirleyandex.ru \\ ${ }^{2}$ Bryansk State University named by academician I.G. Petrovskiy, 241035 Bryansk, Russia \\ golubeva.galya2012@yandex.ru
}

\begin{abstract}
The authors identify ergonomic factors related to the composition, structure and typical functions in the process of taking into account the criteria for the protection of inventions when patenting technical solutions in the field of professional selection and training of operators and drivers of military and civil man-machine complexes. The article describes the ergonomic capabilities of selection methods and devices, technical results from the introduction of virtual, hardware-software and computer simulators for training welders, locomotive drivers, radar systems' operators, operator of remotely piloted aircraft, vehicles' mechanics-drivers. For the selection of patents in subclasses of inventions, criteria for expert evaluation of their ergonomics were first proposed based on such criteria as manageability, serviceability and usability.in total, three experts were involved, and the consistency of the solution (the concordance coefficient) during selection was $\mathrm{w}=0.67$. In advanced research related to the construction of automated patent search systems, it is necessary to develop decisive rules for the selection of inventions. The authors of the article plan to develop criteria for the ergonomics of selected inventions for further analysis of promising systems for selecting and training specialists in such IPC categories as G09B9/00, G06F15/20 and A61B5/16.
\end{abstract}

Keywords: Inventions. Selection. Training. Ergonomics. Human-machineenvironment Systems. Patentability of Technical Solutions. Manageability. Serviceability. Usability.

\section{Introduction}

The problem of professional selection and training of personnel of modern ergatic systems (systems" man-machine-environment") becomes particularly relevant in connection with the need to solve a number of scientific and practical problems to ensure

Copyright (C) 2020 for this paper by its authors. Use permitted under Creative Commons License Attribution 4.0 International (CC BY 4.0).

* Publication financially supported by RFBR grant №19-07-00844 


\section{V. Spasennikov, K. Androsov, G. Golubeva}

the ergonomic efficiency of personnel (operators and drivers of human-machine complexes for civil and military purposes). However, the development and patenting of technical means (methods, devices, software and hardware complexes) as shown in a number of domestic studies to solve the problems of effective selection and training of operators and drivers is given clearly insufficient attention (K. Yu. Androsov, A. N. Sudarik, S. N. Fedotov, 2018 [1], S. V. Kondratenko, A. A. Kuzmenko, V. V. Spasennikov, 2017 [2], M. V. Mikhailyuk, M. A. Torgashev, 2014 [3], A.V. Chuntul, 2019 [4], etc.).

This patent review, which consists of two sections, highlights inventions that are related to the technical and economic effects of the methods' introduction and devices for evaluating the professionally important qualities of operators both during the selection process and during the formation of the formation and development of certain skills and abilities using patented training systems over the past decade. From the General cluster of inventions in the categories of the international patent classification IPCA61B5/00 (satisfaction of human life needs) and IPCG09B9/00 (technical training tools, secret writing, simulators), 10 most interesting methods and devices patented by domestic authors in the field of professional selection and operator activity of modern systems "man-machine-environment" were selected on the basis of an expert survey. The novelty of the patent review is due to the fact that from the General array of inventions, patents that meet such criteria of ergonomics as manageability, serviceability and usability have been selected by experts.

\section{Methods and hardware-software systems for evaluating professionally important qualities for selection operator and driver activities}

This section of the patent review includes four inventions that are related to personal characteristics (the level of human claims); psychophysiological qualities (visual-motor-coordination, vestibular apparatus) and the assessment of the reliability of the necessary knowledge in the selection process for operators' special training.

The basis for selection for driving and operator activities is the diagnosis of human qualities using valid and reliable methods $[1,2,4,5$, etc.].

In the process of selecting operators and diagnosing professional fitness in a number of operator activity's types, the level of claims is a professionally important characteristic. A.D. Ishkov and A.V. Kolesnikov patented a method for diagnosing the level of human claims, which is described in the invention Patent RU2433797, IPCA61B5/16, 30.06.2010 [6].

The patented method involves performing 4 tasks, each of which the subject draws in cells of the set shape and size for a certain time one identical specified figure. The time at which the first and second stage are equal, the execution time of the third stage is less than the time at which the first and second stages of the task execution time, the fourth less than the run time of the third stage of the task.

The task is given to the subject as a test for motor coordination, the true purpose of the study is reported at the end of the work. 
The claim level indicator (LC) is calculated using the formula (1), where AL achievement level:

$$
L C=\frac{\left(L C_{2}-A L_{1}\right)+\left(L C_{3}-A L_{2}\right)+\left(L C_{4}-A L_{3}\right)+\left(C L_{5}-A L_{4}\right)}{4}
$$

In accordance with the indicator of the level of claims of the subject, it is possible to diagnose the level and adequacy of his claims using a correlative norm:

LC $\geq 3,7$-unrealistically high level of claims;

$3,7>\mathrm{LC} \geq 2,2-$ high level of claims;

2.2>LC $\geq 0$-moderate level of claims;

$0>\mathrm{LC} \geq-1.5-$ low level of claims;

$-1,5>\mathrm{LC}-$ unrealistically low level of claims.

The described method is easily automated and can be used in a variant of subjects' group examination.

Employees of the laboratory "Ergatic control systems" of the Volga state technical University (Yoshkar-Ola) developed and patented a method for determining the reaction time of a person to moving objects - Patent RU2686049, IPCA61B5/10, 18.09.2018 [7].

The invention relates to the field of modeling devices, which should be regarded as teaching or training devices, causing students feeling the identical feelings that arise when dealing with real devices, characterized by recording or measuring trainee and is intended to determine human reaction time to moving objects.

The technical result of the proposed ergonomic method for determining the human reaction time to moving objects is to expand the technological capabilities of the known methods by determining the reaction time in the condition of the movement of test objects along various trajectories in a rectangular coordinate system in the space "x-y-z".

At the national research Tomsk Polytechnic University, A. P. Sokolov, Yu. P. Khmelevsky and M. S. Kuhta developed a simulator that can be used to strengthen the musculoskeletal system, as well as to test movement coordination - Patent RU2704143, IPCA63B22/16, 09.04.2019 [8].

The ergonomic advantage of the patented simulator is that it can be used to strengthen the musculoskeletal system during off-season training in extreme sports and in the process of testing movement coordination.

The inventors of the southern Federal University, E. K. Aidarkin and D. N. Shcherbina, developed and patented "Method for evaluating student knowledge in computer testing" - Patent RU2640709, IPCG09B7/06, 11.01.2018 [9].

The invention relates to learning tools in which the student selects the answer to a question from a set of answers simultaneously with the registration of event-related potentials (SSP), and can be used for automated knowledge assessment. The assessment of the increase in the reliability of knowledge was carried out on the basis of distribution's simulation probabilistic modeling of estimates obtained under various testing scenarios.

Situations are modeled on the basis of multiple simulations, taking into account the probability of a random error at the level $p \leq 0.05$. The following situations are simulated: 
- Confident knowledge of the material.

- Uncertain knowledge of the answers to half of the questions, the rest tries to guess based on residual knowledge.

- Confident knowledge of half the material, uncertain knowledge of the rest.

- Residual knowledge is not sufficient to pass the test.

- Random guessing.

- Decommissioning with the involvement of external sources.

- Writing off half of the responses with the involvement of external sources, the rest is random guessing in conditions of lack of time.

The patented method allows you to achieve a new technical result - separating the correct answer based on the student's knowledge from randomly guessing the answer or the answer obtained with the involvement of external sources, as well as separating the wrong one when trying to use partial knowledge from a randomly selected wrong answer.

\section{Virtual, hardware-software and computer simulators for education and training of operators and drivers of systems for various purposes}

A number of inventions of domestic authors are related to the education and training of systems' personnel for various purposes, including patented technical means for training welders, locomotive drivers, driver mechanics and operators of man-machine complexes for military and civil purposes $[5,10,11$, etc.].

A group of authors of Zheldorprogram LLC has patented a simulator for professional training of locomotive drivers and maintenance personnel, - Patent RU2596042, IPCG09B9/00, 21.04.2015 [12].

This invention relates to the field of simulators of railway transport for training traction rolling stock's drivers. The invention can be used in institutes and technical schools for professional training of students to operate safety devices, study the composition of equipment, features of their design, operating principles, perform the main functions of ensuring the safety of train traffic, study the interaction of safety devices with infrastructure devices.

The positive effect of the proposed invention is to expand the functionality and provide increased professional training of locomotive crews and maintenance personnel associated with driving a train.

Inventors V. M. Shurupov and M. A. Kozyrev developed a technical training tool "Simulator for teaching arc welding", - Patent RU2447515, IPCG09B19/24, 08.02.2011 [13].

The invention relates to the field of welding and can be used as a technical tool for teaching techniques and skills in manual and semi-automatic welding.

The technical result and ergonomic advantage of this invention is: ensuring the development of correct psychomotor skills in the trainee to maintain the standard parameters (length of the arc gap, angle of inclination of the welding electrode, devia- 
tion from the center of the cutting edges of the welded parts, welding speed) in various spatial positions; increasing the effectiveness of training by controlling the standard parameters of welding; reducing the cost of the simulator during manufacture; reducing training costs.

A group of military inventors developed and patented the "Virtual simulator of the operator of a remote manned aircraft", - Patent RU2327225, IPCG09B9/32, 04.09.2006 [14].

The invention relates to the field of aviation simulators and can be used for training operators of remotely piloted aircraft (UAVs).

The patented simulator contains a real UAV with standard controls, easy-toremove magnetic "sucker" sensors for roll, pitch, direction and engine control, a UAV control panel with a radio channel that has roll, pitch, direction control knobs, an engine control knob, a motion transfer adapter, a laptop, virtual glasses with a positioning unit.

The use of a virtual simulator of a UAV operator allows you to maintain operators' professionally important qualities and increases the safety of the UAV flight.

Individual and group training of radar operators is associated with the registration of accuracy and time characteristics of the quality of activity, which allows you to exclude blunders of operators in the workplace and assess professional fitness. V. K. Altunin and V. B. Risunkov patented "Simulator for group training of radar operators", Patent RU 2419164, IPCG09B9/40, 30.07.2009 [15].

The invention includes a set of unified training workstations ( URMO), a training management post (PRO), which contains the instructor's workplace (RMI) and a database server.

This simulator makes it possible to ensure the maximum approximation of training to real operating conditions. The invention can be used to form the skills and abilities necessary in real working conditions for radar operators of surface and underwater ships.

The authors of the invention [16] Patent RU2596518, IPCG09B19/00, 28.05.2015 developed a software-hardware simulator instrumentation internal communications switching and control (PAT ASCU), which is designed to teach the principles of working with complex equipment internal communication and switching control ASCU and ASKU together with radio stations and collaboration with a complex of training facilities (CTF) in terms of verbal exchange and remote stations (RS).

The technical result and ergonomic advantage of a patented product is:

- improving the accuracy of external blocks of hardware-software complex ASCU and functional compliance from ASCU;

- ability to work with wired and wireless digital networks.

The inventors V. V. Filippov, N. D. Aleshechkin, and A. A. Radin developed and patented a simulator for training driver mechanics "Computer simulator for initial training of driver mechanics", - Patent RU2190256, IPCG09B9/04 [17].

This invention is intended for training the driver of an armored tracked vehicle.

The structure of computer simulator initial training of the driver introduced a computer monitor installed in front of the viewing device, the mouse or keyboard, which 


\section{V. Spasennikov, K. Androsov, G. Golubeva}

are placed in the cabin, near the cockpit installed, the hardware counter, which are: the block matching devices (QCD), the printer, the power supply apparatus and a computer that includes a system unit of the personal electronic computers (PC), a graphics accelerator device sound processing group of the digital and analog outputs, group digital and analog inputs.

The simulator may not have an instructor's place and can function independently without an instructor, or in a group of 3-9 simulators connected to a computer network with a common training supervisor (instructor), who can take over the functions of setting the simulator's operating mode, working in the "Registration" mode, which will reduce the number of instructors by 3-5 times when training mechanics-drivers to drive combat vehicles.

The use of the proposed simulator will simplify the functions of the instructor for monitoring and evaluating the actions of the trainee by more than $80 \%$, increase the objectivity of control, provide a functional link between the actions of the trainee and the observed changing visual environment, speed up the process of forming the correct driving skills of a combat vehicle by 2 times; reduce the existing consumption of motor resources for driving training by $60 \%$ or more.

As it was shown in the introductory part of the review, the selection of inventions was carried out according to such criteria of ergonomics of technical solutions proposed by the authors using expert assessments (three experts were involved), with the coefficient of agreed expert opinion being $\mathrm{w} \geq 0.87$.

\section{Conclusion}

The conducted ergonomic analysis of patents related to the selection and training of personnel of "human-machine-environment" systems for military and civil purposes based on inventions based on such criteria as manageability, serviceability and adaptability allows us to make some conclusions in conclusion:

1. Methods and devices for selecting and training personnel are complex complexes, modeling and simulation systems, computer programs and physical models, and special techniques created to prepare the operator to make high-quality and timely decisions.

2. In modern simulators and training programs, the principles of developing practical skills with simultaneous theoretical training are laid down. The implementation of this approach has become possible due to the development and cheapening of computer technology and information technology in the field of creating virtual reality. On the basis of training technologies, simulators for military purposes have been developed that allow simulating combat operations in real time, and many applications of virtual reality technology have been created, which make it possible to significantly expand the use of training technologies.

3. Promising ergodesigner developments related to patenting methods and devices for selecting and preparing "human-machine-environment" systems must be equipped with overload simulators. a complete modern simulator system must include, in addition to "visual simulation" means, "sensitive simulation" when simulating the 
situation for a driver, pilot, cosmonaut, tankman or radar operator. When training only on computer simulators, there is a danger of training not real, but "virtual specialists" who are unable to perform tasks in various conditions of professional activity of operators and drivers of human-machine systems for military and civil purposes.

\section{References}

1. Androsov K. Yu., Sudarik A. N., Fedotov S. N. Development of a unified set of tests and its software approbation for solving problems of professional selection in operator and driver activities. Ergodesign 1(01), 28-35 (2018).

2. Kondratenko S. V., Kuzmenko A. A., Spasennikov V. V. Analysis of the dynamics of patenting inventions in the sphere of satisfying human life needs. Bulletin of Bryansk state technical University 4(57), 183-191 (2017).

3. Mikhailyuk M. V., Torgashev M. A. Modeling and visualization of threedimensional virtual control panels in simulators. Scientific visualization 4, 50-60 (2014).

4. Chuntul A.V. Ergonomic support for the development of modern and advanced systems "crew-helicopter-environment". Ergodesign 4 (06), 147-155 (2019).

5. Kotenko K. A., Spasennikov V. V. Problems of assessing the impact of the implementation of ergonomic requirements on the economic efficiency of humanmachine complexes. Economic analysis: theory and practice 4(451), 149-163 (2016).

6. Ishkov A.D., Kolesnikov A.V. Patent RU2433787. A method for diagnosing the level of human claims, IPCA61B5/16 (2010).

7. Kuralov P. A., Glazyrin A.V. Patent RU2686049. Method for determining the reaction time of a person to moving objects, IPCA61B5/00. (2018).

8. Sokolov A. P., Khmelevsky Yu. P., Kuhta M. S. Patent RU2704143. Simulator, IPCA63B22/16. (2019).

9. Shcherbina D. N., Aidarkin E. K. Patent RU2640709. Method for evaluating a student's knowledge in computer testing, IPCG09B9/06. (2018).

10. Androsov A. A., Malakhov Yu. A. Review of innovative devices for monitoring human wakefulness in conditions of monotonous activity. Ergodesign 2(04), 92-96 (2019).

11. Klimov A. A., Zarechkin E. Yu., Kupriyanovsky V. P. About the features of using simulators in the implementation of educational programs. Modern information technologies and it education 15(2), 477-487 (2019).

12. Bazyuk A.M., Viskov V. V., Guryanov A.V., Shukhin A. E. Patent RU2596042. Simulator for professional training of locomotive drivers and maintenance personnel, IPCG09B9/00. (2015).

13. Shurupov V. M., Kozyrev M. A. Patent RU2433787. Simulator for training electric arc welding, IPCG09B19/24. (2011).

14. Merkulov V. P., Zakharov V. K., Vislyaev K. S., Maklishaevsky V. Ya., Gromov V. A., Muzhichek S. M. Patent RU2327225. Virtual simulator of the operator of a remote manned aircraft, IPCG09B9/32. (2006). 
8 V. Spasennikov, K. Androsov, G. Golubeva

15. Altunin V. K., Risunkov V. B. Patent RU2419164. Simulator for group training of radar operators, IPCG09B9/40. (2009).

16. Zinkov A. A., Kharlamov M. V., Barabanov O. A., Mishkov A.M. Patent RU2596518. Software and hardware simulator of internal communication switching and control equipment, IPCG09B19/00. (2015).

17. Fillipov V. V., Aleshechkin N. D., Radin A. A. Patent RU2190256. Computer simulator for initial training of a driver-mechanic, IPCG09B9/04. (2001). 